\title{
Powder and Solvent for Intravesical Solution Dosage Form
}

National Cancer Institute

\section{Source}

National Cancer Institute. Powder and Solvent for Intravesical Solution Dosage Form.

NCI Thesaurus. Code C149786.

Powder and solvent intended for the preparation of an intravesical solution by dissolving the powder in the solvent. 